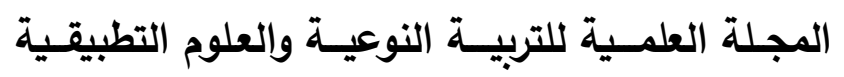

The Scientific Journal of Specific Education and Applied Sciences

\title{
How Group Size and Blog Characteristics Influence \\ Critical Thinking in Online Discussion
}

\author{
Radwa Amir Salah \\ Faculty of Specific Education - Fayoum University
}

\begin{abstract}
In this investigation, the aim was to assess the impact of the interaction between two types of blog post characteristics and the group size on developing critical thinking skills in online discussion. This study was exploratory and interpretative in nature, for this purpose a collaborative learning environment based on educational blogs was designed according to international standards. The methodological approach taken in this study is a mixed methodology based on descriptive and the semi-experimental approach. The study sample was divided into four groups namely, Group (A) was interacted through "separate blogs with detailed comments", and group (B) was interacted through "sequential blogs with detailed comments", while group (C) interacted through "separate blogs with concise comments", and group (D) interacted through "sequential blogs with concise comments". The most obvious finding to emerge from the analysis was that critical thinking skills have been developed in groups $\mathrm{A}, \mathrm{B}$, and $\mathrm{C}$. However, the results of this study did not show any significant improvement in group D. The findings of this study have a number of important implications for future practice.
\end{abstract}

Key words: blogging, engaging in learning, communicative theory, critical thinking 


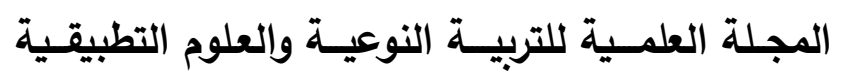

The Scientific Journal of Specific Education and Applied Sciences

\section{Introduction}

The Internet has witnessed a huge flow of information through the second generation of the Web (Web 2.0) tools, which in turn reflected on the ability of students to share digital content faster than it ever before (Luckin et al., 2009). Blogs have become one of the most popular social Web 2.0 tools, which increased users' interactions in online content creation and reciprocal ideas. Blogs allows faculty members to create collaborative learning content, while enhancing students' opportunities to communicate with peers across the web and to have the opportunity to comment and provide feedback on their articles and research questions (Yousef et al., 2020). Therefore, blogs discussions contribute to achieving a number of social, emotional and intellectual goals. For instance, it helps students to be more aware of the various opinions on the issues of the debate, and enables them to understand the complexity of some issues, because they may come out of the discussion with more questions, and this helps them in thinking in all likelihood, then students distinguish between facts and opinions, and when students share these ideas, learning reaches the highest levels of thinking e.g. critical thinking.

Student bloggers can create an immersive social learning environment where they can learn from the ideas of peers, exchange information resources and can post their personal comments and feedback on other peers' blogs (Johnson, \& Levine, 2008). In the same note, many scholars examine the tendencies and desires of learners towards learning through the blogs. These studies further support the effective blogging as communicative tools for both individual self-expression and social communication to provide free space for learners to communicate and share the commonality of interest. 


\section{المجـلة العلمـية للتربيـة النوعيـة والعلوم التطبيقـية}

\section{The Scientific Journal of Specific Education and Applied Sciences}

The correlation between blogging and development of some thinking skills, in particular critical thinking for university student, was the focus of attention of Daniel J. Levitin, Professor of Mental Health and Behavioral Neuroscience at McGill University in Montreal, Canada, who discussed critical thinking skills and how students discussing different opinions to determine the correct ones and the incorrect ones, and evaluating opinions in an objective way away from bias, including data and knowledge published on social media, such as blogs and free chat communities, and encyclopedias such as Wikipedia and other sources. Across the web available(Levitin, 2016). Hence the importance of developing critical thinking skills among university students has become an imperative in the digital age, considering this blogging is closely related to the skills of critical thinking.

The remaining parts of the paper proceeds as follows: First gives a brief overview of research problem and design. It will then go on to the implementations details of the social learning-oriented instructional blogs. The last section presents the findings of the research and highlights further studies that could also be conducted to enhance students' reflection of the learning topics and apply diverse some critical thinking skills.

\section{Research Problem}

Several lines of evidence suggest that the learners' characteristics affect student involvement and learning (Halverson \& Graham, 2019), the size of the discussion group and blog post characteristics are two major factor that influence learner's behavior and thinking. Therefore, this research question was: How does the size of the group and the different design of blog post characteristics influence student critical thinking skills? 


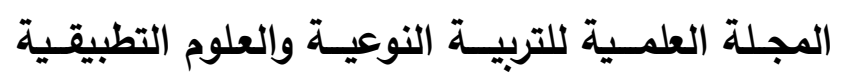

The Scientific Journal of Specific Education and Applied Sciences

\section{Research Design}

There is a growing body of literature that recognizes blogging as a behavior of social knowledge construction, and the use of blogs in online educational settings has the potential to enhance critical thinking among students (Chamberlain, 2017). This study provides new insights into understand through in-depth qualitative analysis how students perceive their critical thinking while using their blog discussion. The population of this research consists of blog posts and comments posted on CSlab platform that was designed to introduce and encourage interaction among learners in the "Introduction to Computers" course offered by Fayoum University. The cohort was divided into four groups according to the different types of blog post characteristics and different group size as illustrated in table 1.

Table 1: Describing the characteristics of the sample.

\begin{tabular}{c|c|c|c|c}
\hline $\begin{array}{c}\text { Group } \\
\text { ID }\end{array}$ & \multicolumn{2}{|c|}{ Blog Characteristics } & \multirow{2}{*}{ Group Size } & $\begin{array}{c}\text { Group } \\
\text { Patterns }\end{array}$ \\
\cline { 1 - 3 } Blog A & $\begin{array}{c}\text { Discussion } \\
\text { Patterns }\end{array}$ & $\begin{array}{c}\text { Comments } \\
\text { Length }\end{array}$ & 13 & Medium \\
\hline Blog B & Sequential & Detailed & 13 & Medium \\
\hline Blog C & Separate & Concise & 10 & Small \\
\hline Blog D & Sequential & Concise & 17 & Large \\
\hline
\end{tabular}

\section{Research Methodology}

This investigation takes the form of a case-study of the investigate whether the social interaction patterns influence how knowledge is constructed based on connectivism learning theory (Yin, 2017). Considering that, the aim of the present research was to investigate the relationship between different types of blog post characteristics 


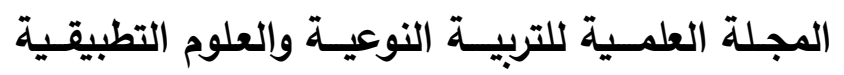

The Scientific Journal of Specific Education and Applied Sciences

(e.g. separate - sequential and its comments length e.g. detailed concise) and different size of group discussion, in order to support critical thinking skills among students. Figure 1. Presents an overview of research design.

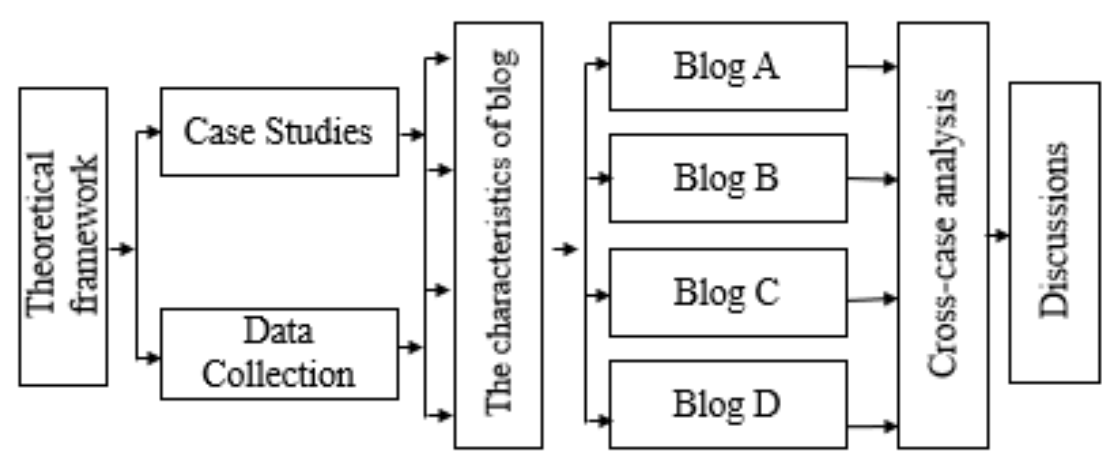

Figure 1: Case study research methodology adapted from (Yin 2017).

\section{Research Hypothesis}

The current study, based on connectivism learning theory, where student bloggers can learn from the each other's ideas, share knowledge resources in their network. This study uses a qualitative case study approach to investigate the following hypothesis:

H1. The different blog design characteristics are significantly affecting the development of critical thinking skills.

H2. The different of the size of the group involved in blogging discussions (large vs. medium vs. small) are significantly affecting the development of critical thinking skills. 


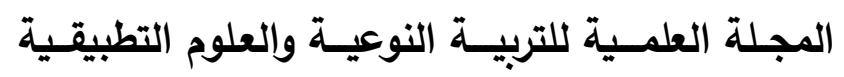

The Scientific Journal of Specific Education and Applied Sciences

\section{Theoretical Background}

Connectivism is the integration of principles explored by chaos, network, and complexity and self-organization theories (Siemens, 2004). In connectivism, the collective connection between all the "nodes" in a network is what gives rise to new forms of knowledge. According to Siemens (2004), knowledge is created beyond the individual level of human participants and is constantly changing. Knowledge in networks is not controlled or created by any formal organization, however organizations can and should "connect" to this constantly flowing world of information and extract its meaning.

Knowledge in connectivism is chaotic, it manifests itself between the nodes that come and go and the information flows through networks interconnected with many other networks. The importance of connectivism is that its proponents argue that the network connections changes the essential nature of knowledge (Bates, 2018). Garcia et al., (2014) identified the relationships that exist between learners within the blogging platforms and the manner in which teaching staff may input into the community but will not automatically participate in the learning environment (Garcia, 2014). 


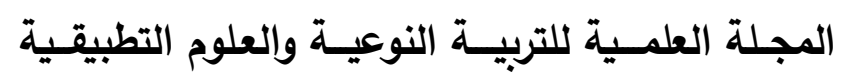

The Scientific Journal of Specific Education and Applied Sciences

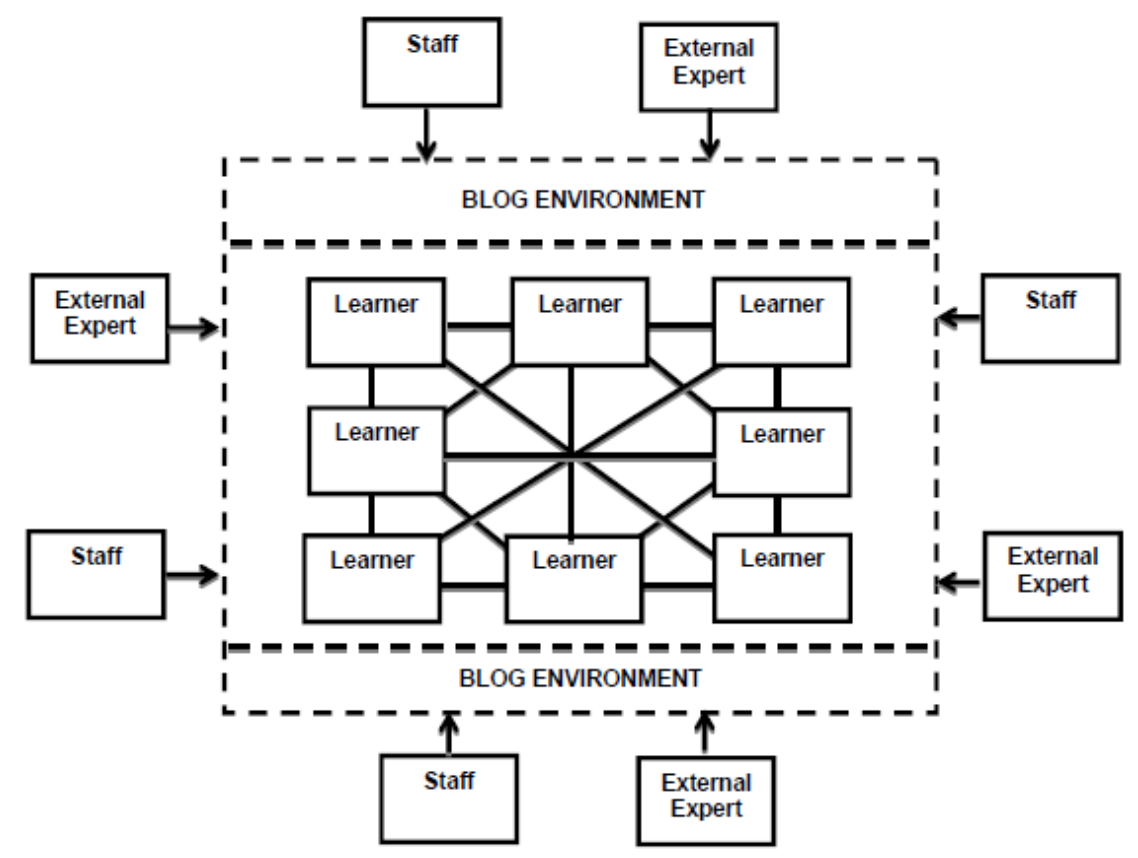

Figure 2: Connectivist educational blog model (Garcia et al., 2014)

\section{Blogs and Critical Thinking Skills}

Critical thinking is a process that aims to analyze, understand or evaluate the way in which knowledge that aims to interpret and represent the world is organized, in particular the opinions or statements that in daily life are often accepted as true (Ennis, 1993). It is defined, from a practical point of view, as the process by which knowledge and intelligence are used to arrive effectively at the most reasonable and justified position on a topic (Brookfield, 2020).

Many recent studies e.g. Dr. Richard Paul and Dr. Linda Elder, from the Foundation for critical thinking, point out the seven Universal Intellectual Standards that should be applied to thinking whenever you want to assess quality reasoning about a problem, topic, or situation; Critical thinking involves mastering these standards as summarized in Figure 3 (Paul, \& Elder, 2019). 


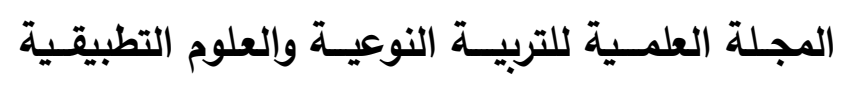

The Scientific Journal of Specific Education and Applied Sciences

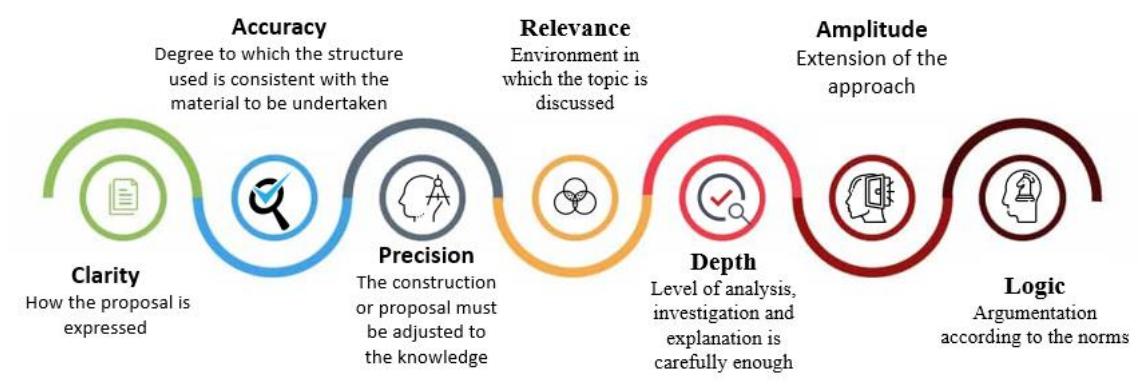

Figure 3: Critical thinking standards (Designed by the author)

Therefore, when searching for truth, it is necessary to avoid fallacies or vices of reasoning. It is very important not to fall into wishful thinking, which is the opposite of critical thinking, since it lacks rational solidity and is based on unwarranted likes, desires, illusions or assumptions that lack evidence or verifiable data (Paul, \& Elder, 2019). The truth obtained through critical reasoning is solid compared to the happy lie that is fabricated through magical thinking.

This project was conceived during my time working on why is it important to instill education with critical thinking to improve our learner's way of thinking and how they learn? This is because a student who analyzes and thinks critically before acting is automatically a student who can contribute positively to society.

This project at hand was conceived during my time working as an assistance lecture at the faculty of specific education, Fayoum University. I argue that critical thinking implies that one must be "focused", in the sense that it is not simply thinking, but thinking about something that we want to understand and do in the best possible way. In this way, the process can be appreciated and evaluated so that "decisions" can be made during it. The development of critical thinking, closely linked to the expansion of 


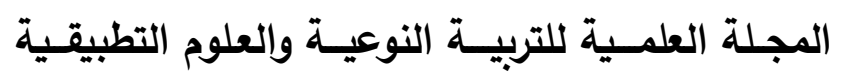

The Scientific Journal of Specific Education and Applied Sciences

knowledge, requires an effective learning environment e.g. blogs as social learning tool. Considering these ideas and related work, this study set out to investigate whether the social interaction patterns influence the development of critical thinking based on connectivism learning theory.

\section{CSLab Blog Platform Design}

Wang et al., (2014) demonstrated that "blog-based learning systems have the characteristics of dynamic knowledge repositories and knowledge maps. However, traditional e-learning systems have only predetermined knowledge contents and knowledge maps.". Thus, current research designed an interactive blog-based environment for bridging the learning management system limitations. The following part of this paper moves on to describe in greater detail how we designed the CSlab.

\section{CSLab Prototype}

Paper prototyping is a commonly used method for the early stages of user interface design (Sefelin, 2003). This project follows paper prototypes as an appropriate medium for iterative CSLab design. This section reports our experience when doing paper prototypes test with students of the faculty of specific education as the main target users. We divided the paper prototyping test for CSLab into three major parts. The first part was including preparing the paper prototype, visualize concepts and ideas, determining the aim of the test, defining scenario and tasks for the participant.

In the second part the interface mockup of the application using paper hand drawings was designed. Then, gives a brief introduction for the students who are volunteered to participate in this test about the idea behind CSLab and its objectives. Now move on to the third part of the test to process concrete tasks with the prototype built from current used scenarios as can be seen in Figure. 4. In order to 


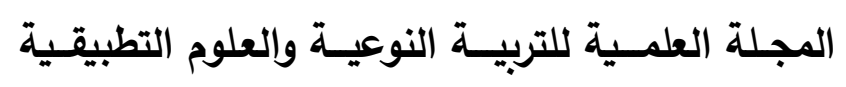

The Scientific Journal of Specific Education and Applied Sciences

evaluate a paper prototype a user interview was conducted. $86 \%$ of those who were interviewed indicated that the system supports selfself-directed and collaborative content sharing. Moreover, $90 \%$ of the students regarding the system functions (e.g. comments system, sharing, and analytics provided of the CSLab system), reported that the system was appropriate and easy to use. Furthermore, the functions fit well to their learning needs.

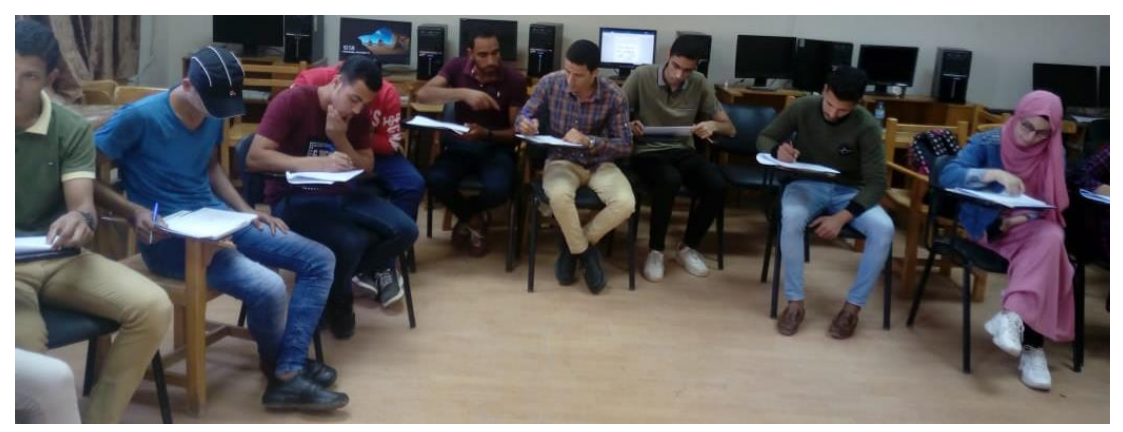

Figure 4: CSLab paper prototype test $(\mathrm{N}=21)$.

\section{CSLab Implementation}

In the following section we will describe CSLab with an eye on the implementation details.

\section{Design requirements}

- The environment must have a separate system for each of the four groups.

- The environment must be secured with SSL Certificates to give students full privacy when browsing and dealing with the environment through the https: // protocol

- Securing databases and the main server so that it should not contain electronic vulnerabilities such as SQL-Injection or Cross Site 


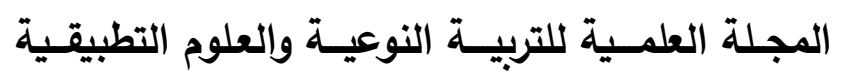

The Scientific Journal of Specific Education and Applied Sciences

- The Host Server Bandwidth environment has an open download space to accommodate the large number of interactions and learning resources available.

- The environment allows single sign-on through student accounts on social media (Google, Facebook, Twitter) with full data encryption.

Reliability and error-free download guarantee.

- Page mode (About us / Contact us)

\section{Technical and pedagogical criteria for designing the CSLab}

The design of blog scope is very important to present the content of the blog. Thus, the information in blog should be in-depth of the discussion subject (Yousef, Rößling, 2013). In addition, blog title should attract the learners to the topic and easy to be understood by them (Kim, 2008). Also, the blog title should include short description of the blog topic and blog should include intrinsic value of information to the subject cover. The content in blog should express its objectives and reflect the level of difficultness, sequences and quality of content sufficient to meet the learning objective (Yousef, Rößling, 2013). Owing to learning objective used to plan and arrange the learning process, also to control the learning outcome (Sun et al., 2008). Consequently, the blog should be set on clearly defined objectives and student should be invited to set their own goals in order to encourage self-regulated learning (Sun et al., 2008). Moreover, information presented in blogs should be met the learning objective and using the bloom taxonomy for design learning objectives. Moreover, information presented in blogs should meet the learning objective and use the bloom taxonomy for designing learning objectives (Yousef et al., 2014). 


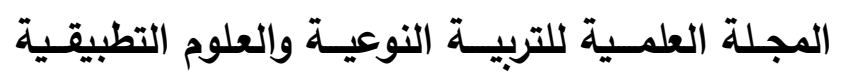

The Scientific Journal of Specific Education and Applied Sciences

\section{CSLab Technologies}

In this step, all previous paper designs were translated into a living model for the interactive environment through programming languages, and it was based on a number of technologies in building the environment as follows:

\section{Programming Languages}

HTML, CSS, and Java Script are used in the design.

\section{Node.JS Library}

It is a software system designed to write applications of scalable web environments as web servers that use Nodejs V8 JavaScript engine, and therefore from this principle the superior speed of Node.js is due to two factors, namely, Node.js is a JavaScript runtime built on Chrome's V8 JavaScript engine. Moreover, Node.js uses an event-driven, asynchronous non-blocking I/O model. Figure 5 show the CSLab interface design .

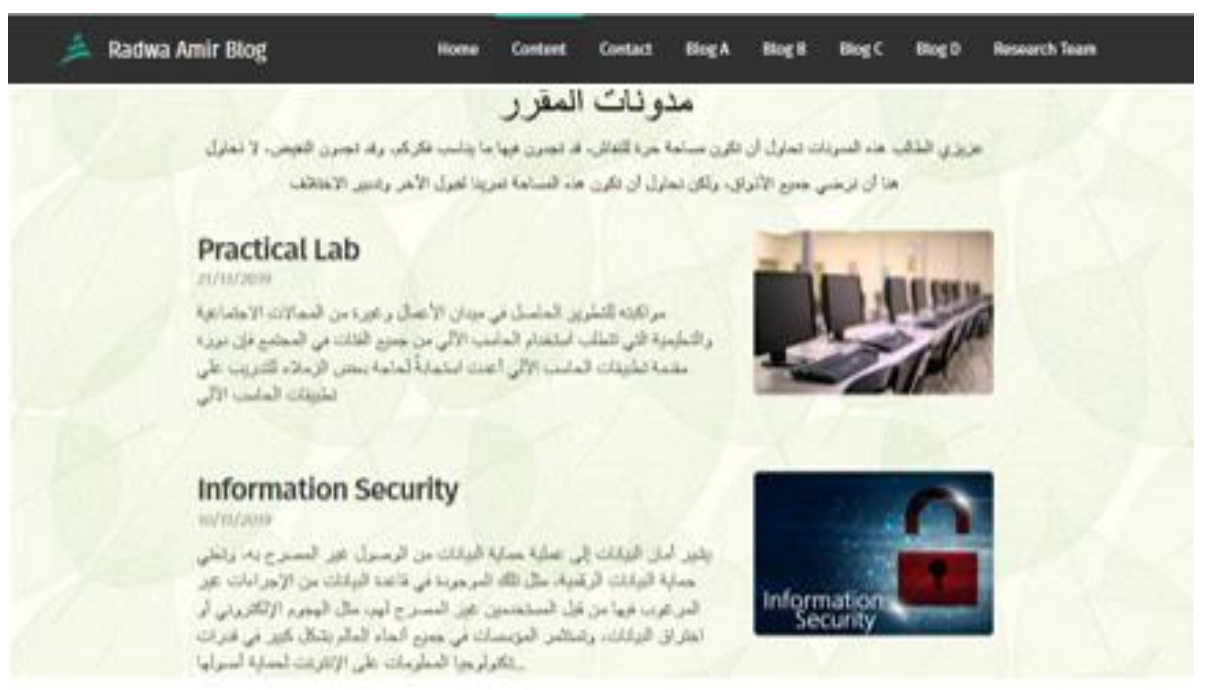

Figure 5: CSLab interface design 


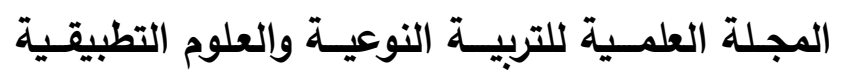

The Scientific Journal of Specific Education and Applied Sciences

\section{Usability Evaluation of CSLab}

The System Usability Scale (SUS) as a general usability evaluation was employed (Brooke, 2013). SUS consists of a 10-item Likertscale questionnaire. Students was asked to rank each question for respondents; from Strongly agree (5) to Strongly disagree (1) based on how much they agree with the item. The results obtained from the SUS analysis are summarized in Figure 6.

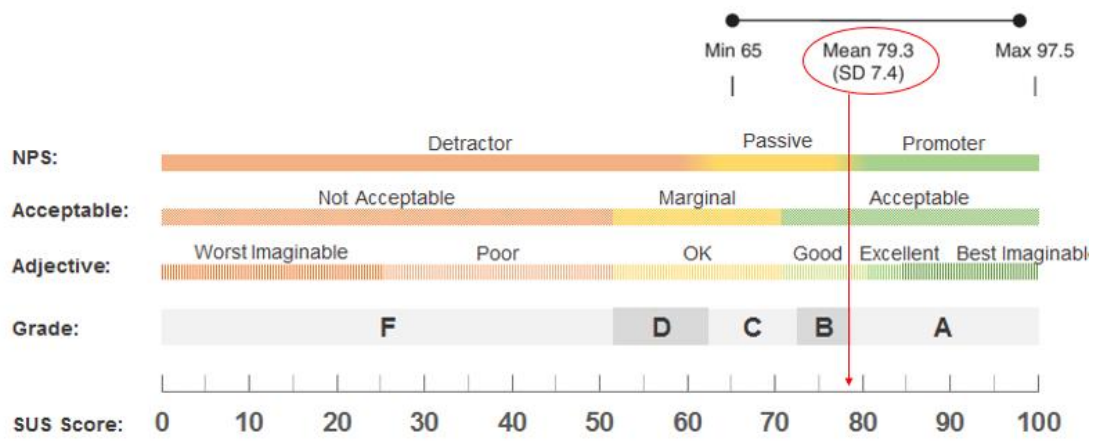

Figure 6: System Usability Scale Results

Cslab obtained a high score around (79.3) According to Brooke (2013) 80.0 or higher is a level (A) which means students like the system and they will recommend it to their friends.

\section{Case Study}

CSLab blogs were used for the "Introduction to Computers" course. This course provides a general introduction to computers, operating systems, hardware, software, and information systems. Emphasis will be placed on computer literacy topics such as hardware, software, operating systems, information security, communications, and network. In this course thinking critically requires using the ability to reason. It is about actively learning, rather than being a passive recipient of information. Students who use critical thinking 


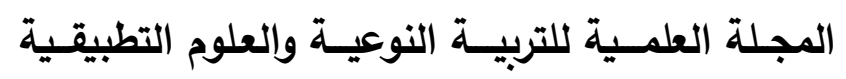

The Scientific Journal of Specific Education and Applied Sciences

question ideas, instead of assuming and accepting them as they come to us. They also seek to determine whether their ideas, arguments, and findings represent the big picture and are open to finding information that contradicts them. The sample was distributed into four main groups (large vs. medium vs. small) as follow:

\section{$\operatorname{Blog} \mathbf{A}$}

The first group of 13 students was interacted through "Separate blogs with Detailed comments". In this group comments were restricted to 100 words and learners are asked to post their comments separately as standalone posts.

\section{Blog B}

The second group of 13 students was interacted through "Sequential blogs with Detailed comments". In this group comments were restricted to 100 words and learners are asked to respond to comments by posted by their peers. Peer response is a form of collaborative learning in blogs where learners can respond to specific parts they don't understand in the original post or comments

\section{$\operatorname{Blog} \mathbf{C}$}

The third group of 10 students was interacted through "Separate blogs with Concise comments". In this group comments were restricted to only 20 words and learners are asked to post their individual comments separately as standalone posts.

\section{Blog D}

The fourth group of 17 students was interacted through "Sequential blogs with Concise comments". The comments were restricted to 


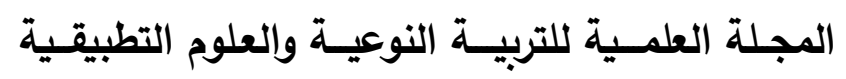

The Scientific Journal of Specific Education and Applied Sciences

only 20 words and leaners were asked to interact to their peer's post and comments.

\section{Results}

Numerous attempts have been made to measure critical thinking skills for different age groups, many of which have been linked to learning theories, methods and approaches to education, and to the analysis of many standards of critical thinking, including the Cornell Critical Thinking Scale, the Watson Scale, the Sayed Sobhi et al. (2015) Scale by extrapolating and analyzing all the previous metrics. The scale of Syed Subhi et al., (2015) is appropriate for the subject of the current study. Sayed Sobhi et al. (2015) Scale for critical thinking includes social skills related to discussion and participation, as the study included three main dimensions, namely cognitive dimension, emotional skills dimension, social skills dimension.

To verify group equality before the case study, the variance of the pre- test critical thinking scale was analyzed to see if there were statistically significant differences between the mean scores of students in the four groups, Table (2) shows these results. By extrapolating the results, it is clear that there are no differences between the experimental groups in the scores of the critical thinking scale, as the value of $(\mathrm{F})$ in critical thinking as a whole (2.001) is not significant at the level of (0.05).

Table 2: Results of analysis of variance in the pre-test in critical thinking

\begin{tabular}{c|l|l|l|l|l|l}
\hline Variable & \multicolumn{1}{|c|}{ Source } & DF & $\begin{array}{l}\text { Sum of } \\
\text { squares }\end{array}$ & $\begin{array}{l}\text { Squares } \\
\text { average }\end{array}$ & F & Sig \\
\hline \multirow{2}{*}{$\begin{array}{c}\text { Critical } \\
\text { Thinking } \\
\text { Scale }\end{array}$} & Between groups & 3 & 2797.4 & 932.4 & 2.001 & $\begin{array}{l}\text { Not } \\
\text { Sig }\end{array}$ \\
\cline { 2 - 6 } & Within groups & 49 & 22830.1 & 465.9 & & \\
\hline
\end{tabular}




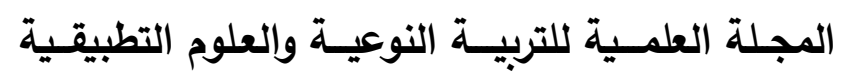

The Scientific Journal of Specific Education and Applied Sciences

There are many students who can think critically but not show it through their actions or simply not want to contribute to society through what they do. But at least it is guaranteeing that individuals are aware of their actions and that this way they may develop that desire to contribute to society in the future.

Therefore, based on the results in Table 2, improving critical thinking to students of Faculty of Specific Education would greatly benefit them and improve their ability to take conscience and responsibility for their actions. This can be achieved after instilling this habit of thinking and analyzing critically. By including this within the educational system, students will change their way of thinking and really come to understand how they are a key part of the learning puzzle.

In the new learning strategies, critical thinking skills have taken over the tasks of teaching and education. The education system is versatile and performs a series of responsibilities, such as taking care of students and raising them, construct personally reflected knowledge adapted to one's individual needs from information represented in cyberspace, spreading knowledge, and meeting the needs of the labor market.

\section{Hypothesis Verification}

In response to the first hypothesis "The different blog design characteristics are significantly affecting the development of critical thinking skills" a T-Test was conducted to reveal the mean differences between groups as shown in tables $(3,4,5,6)$, accompanied by the researchers' interpretation of these results in light of the study variables refer to table (1). 


\section{المجـلة العلمـية للتربيـة النوعيـة والعلوم التطبيقـية}

The Scientific Journal of Specific Education and Applied Sciences

Table 3: The first group “T” test for Critical Thinking Scale ( $=13$ Medium)

\begin{tabular}{c|l|c|c|c|c}
\hline NO & \multicolumn{1}{|c|}{ Sub-metrics } & Mean & SD & T & Sig \\
\hline 1 & Prediction & 2.02 & 1.23 & 8.08 & Sig \\
\hline 2 & Investigation & 2.69 & 2.76 & 3.56 & Sig \\
\hline 3 & Controversial Thinking & 1.76 & 2.31 & 2.75 & Not Sig \\
\hline 4 & Flexibility & 2.15 & 2.15 & 3.60 & Sig \\
\hline 5 & Logical Reasoning & 2.00 & 1.91 & 3.76 & Sig \\
\hline 6 & Generate Solutions & 1.61 & 2.50 & 2.32 & Not Sig \\
\hline 7 & Mental Perseverance & 3.07 & 2.53 & 4.38 & Sig \\
\hline 8 & Ability to Ask & 1.92 & 2.28 & 3.03 & Not Sig \\
\hline Cognitive Dimension & 17.22 & 14.03 & 4.54 & Sig \\
\hline 1 & Emotional courage & 1.61 & 2.59 & 2.24 & Not Sig \\
\hline 2 & Curiosity & 2.15 & 1.57 & 4.93 & Sig \\
\hline 3 & Identify the issues & 1.76 & 2.00 & 3.18 & Sig \\
\hline 4 & Intellectual justice & 2.23 & 1.92 & 4.18 & Sig \\
\hline Emotional Skills Dimension & 7.76 & 6.24 & 4.48 & Sig \\
\hline 1 & Evaluating negative events & 1.61 & 2.81 & 2.06 & Not Sig \\
\hline 2 & Evaluating Positive event & 1.61 & 2.10 & 2.76 & Not Sig \\
\hline 3 & Controversy and dialogue & 2.00 & 2.54 & 2.83 & Not Sig \\
\hline 4 & Decision Making & 0.92 & 1.65 & 2.01 & Not Sig \\
\hline Social Skills Dimension & 6.15 & 7.51 & 2.95 & Not Sig \\
\hline Total Critical Thinking Scale & 31.13 & 27.78 & 4.19 & Sig \\
\hline & & & & & \\
\hline
\end{tabular}




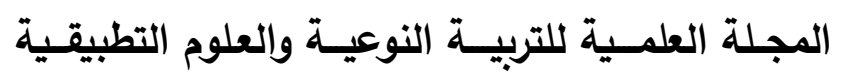

The Scientific Journal of Specific Education and Applied Sciences

Table 4: The Second group "T" test for Critical Thinking Scale $(\mathrm{N}=13)$

\begin{tabular}{|c|c|c|c|c|c|}
\hline NO & Sub-metrics & Mean & SD & $\mathbf{T}$ & Sig \\
\hline 1 & Prediction & 2.32 & 3.08 & 2.60 & Not Sig \\
\hline 2 & Investigation & 3.30 & 2.32 & 5.13 & Sig \\
\hline 3 & Controversial Thinking & 2.76 & 2.52 & 3.95 & Sig \\
\hline 4 & Flexibility & 3.00 & 2.23 & 4.35 & Sig \\
\hline 5 & Logical Reasoning & 2.53 & 2.76 & 3.34 & Not Sig \\
\hline 6 & Generate Solutions & 2.53 & 2.18 & 4.19 & Sig \\
\hline 7 & Mental Perseverance & 4.84 & 3.03 & 5.72 & Sig \\
\hline 8 & Ability to Ask & 2.30 & 2.42 & 3.42 & Sig \\
\hline $\operatorname{Cog}$ & itive Dimension & 23.49 & 16.09 & 5.27 & Sig \\
\hline 1 & Emotional courage & 2.92 & 2.59 & 4.05 & Sig \\
\hline 2 & Curiosity & 3.23 & 2.24 & 5.19 & Sig \\
\hline 3 & Identify the issues & 1.61 & 2.21 & 2.62 & Not Sig \\
\hline 4 & Intellectual justice & 2.00 & 1.87 & 3.85 & Sig \\
\hline Emo & tional Skills Dimension & 9.76 & 6.75 & 5.21 & Sig \\
\hline 1 & Evaluating negative events & 0.92 & 2.53 & 1.31 & Not Sig \\
\hline 2 & Evaluating Positive event & 1.53 & 2.22 & 2.49 & Not Sig \\
\hline 3 & Controversy and dialogue & 3.23 & 3.21 & 3.62 & Sig \\
\hline 4 & Decision Making & 2.23 & 2.38 & 3.40 & Sig \\
\hline \multicolumn{2}{|c|}{ Social Skills Dimension } & 8.53 & 9.10 & 3.83 & Sig \\
\hline \multicolumn{2}{|c|}{ Total Critical Thinking Scale } & 41.78 & 29.06 & 5.11 & Sig \\
\hline
\end{tabular}




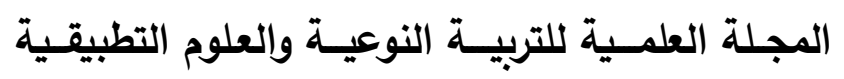

The Scientific Journal of Specific Education and Applied Sciences

Table 5: The Third group " $T$ " test for Critical Thinking Scale $(\mathrm{N}=10)$

\begin{tabular}{|c|c|c|c|c|c|}
\hline NO & Sub-metrics & Mean & SD & $\mathbf{T}$ & Sig \\
\hline 1 & Prediction & 3.30 & 2.71 & 3.85 & Sig \\
\hline 2 & Investigation & 2.30 & 2.54 & 2.86 & Not Sig \\
\hline 3 & Controversial Thinking & 1.70 & 2.65 & 2.04 & Not Sig \\
\hline 4 & Flexibility & 2.60 & 2.79 & 2.94 & Not Sig \\
\hline 5 & Logical Reasoning & 1.80 & 2.09 & 2.71 & Not Sig \\
\hline 6 & Generate Solutions & 2.00 & 3.16 & 2.00 & Not Sig \\
\hline 7 & Mental Perseverance & 5.50 & 3.74 & 4.63 & Sig \\
\hline 8 & Ability to Ask & 2.50 & 2.95 & 2.67 & Not Sig \\
\hline $\operatorname{Cog}$ & itive Dimension & 21.70 & 17.87 & 3.84 & Sig \\
\hline 1 & Emotional courage & 2.50 & 3.24 & 2.44 & Not Sig \\
\hline 2 & Curiosity & 3.40 & 2.87 & 3.74 & Sig \\
\hline 3 & Identify the issues & 1.60 & 2.06 & 2.44 & Not Sig \\
\hline 4 & Intellectual justice & 2.40 & 1.64 & 4.60 & Sig \\
\hline Emo & ional Skills Dimension & 9.90 & 7.57 & 4.13 & Sig \\
\hline 1 & Evaluating negative events & 2.50 & 2.63 & 3.00 & Not Sig \\
\hline 2 & Evaluating Positive event & 1.70 & 1.76 & 3.04 & Not Sig \\
\hline 3 & Controversy and dialogue & 3.70 & 2.31 & 5.06 & Sig \\
\hline 4 & Decision Making & 1.90 & 1.79 & 3.35 & Not Sig \\
\hline \multicolumn{2}{|c|}{ Social Skills Dimension } & 9.80 & 7.53 & 4.11 & Sig \\
\hline \multicolumn{2}{|c|}{ Total Critical Thinking Scale } & 41.40 & 29.99 & 4.40 & Sig \\
\hline
\end{tabular}




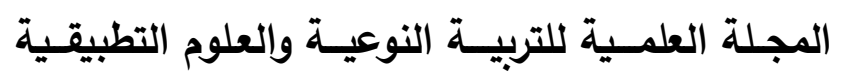

The Scientific Journal of Specific Education and Applied Sciences

Table 6: The Forth group " $T$ " test for Critical Thinking Scale $(\mathrm{N}=17)$

\begin{tabular}{c|l|c|c|c|c}
\hline NO & \multicolumn{1}{|c|}{ Sub-metrics } & Mean & SD & T & Sig \\
\hline 1 & Prediction & 1.41 & 2.39 & 2.42 & Not Sig \\
\hline 2 & Investigation & 1.17 & 2.87 & 1.68 & Not Sig \\
\hline 3 & Controversial Thinking & 0.70 & 2.25 & 1.28 & Not Sig \\
\hline 4 & Flexibility & 1.17 & 2.03 & 2.38 & Not Sig \\
\hline 5 & Logical Reasoning & 1.35 & 1.69 & 3.40 & Not Sig \\
\hline 6 & Generate Solutions & 1.76 & 2.10 & 3.54 & Sig \\
\hline 7 & Mental Perseverance & 2.11 & 3.23 & 2.69 & Sig \\
\hline 8 & Ability to Ask & 1.47 & 2.40 & 2.52 & Not Sig \\
\hline Cognitive Dimension & 11.17 & 10.82 & 4.25 & Not Sig \\
\hline 1 & Emotional courage & 1.23 & 2.13 & 2.40 & Not Sig \\
\hline 2 & Curiosity & 1.29 & 2.17 & 2.45 & Not Sig \\
\hline 3 & Identify the issues & 0.88 & 2.05 & 1.76 & Not Sig \\
\hline 4 & Intellectual justice & 0.70 & 1.53 & 1.90 & Not Sig \\
\hline Emotional Skills Dimension & 4.11 & 5.09 & 3.33 & Not Sig \\
\hline 1 & Evaluating negative events & 2.35 & 2.19 & 0.44 & Not Sig \\
\hline 2 & Evaluating Positive event & 0.70 & 2.20 & 1.32 & Not Sig \\
\hline 3 & Controversy and dialogue & 0.76 & 3.17 & 0.99 & Not Sig \\
\hline 4 & Decision Making & 0.47 & 1.50 & 1.28 & Not Sig \\
\hline Social Skills Dimension & 4.28 & 5.49 & 1.63 & Not Sig \\
\hline Total Critical Thinking Scale & 19.56 & 21.40 & 3.94 & Not Sig \\
\hline
\end{tabular}




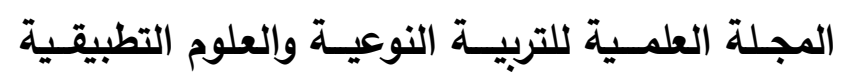

The Scientific Journal of Specific Education and Applied Sciences

Through the data obtained as a result of the post-test of the critical thinking scale, the results of the four experimental groups were analyzed, and the "two-way variance analysis" method (ANOVA) was used to measure the interaction between the two independent study variables, and to identify the significance of the differences between the four experimental groups in addition to Measuring the main effect of each of the study's two independent variables on developing critical thinking skills. Table (7) shows the mean and standard deviations and the bi-directional variance analysis of the four groups considering the dependent variables.

Table 7: Results of analysis of variance in the post-test in critical thinking

\begin{tabular}{c|l|l|l|l|l|l}
\hline Variable & Source & DF & $\begin{array}{c}\text { Sum of } \\
\text { squares }\end{array}$ & $\begin{array}{l}\text { Squares } \\
\text { average }\end{array}$ & F & Sig \\
\hline \multirow{2}{*}{$\begin{array}{c}\text { Critical } \\
\text { Thinking } \\
\text { Scale }\end{array}$} & Between groups & 3 & 754.5 & 251.15 & 2.40 & $\begin{array}{l}\text { Not } \\
\text { Sig }\end{array}$ \\
\cline { 2 - 6 } & Within groups & 49 & 5116.6 & 104.4 & & \\
\hline
\end{tabular}

Closer inspection of the table (3) shows that that there is a positive correlation between the blog design characteristics and the comment on developing critical thinking skills of the first experimental group, by shedding more light on the results of the "T" test, we find that mental skills Cognitive and emotional skills obtained the highest value of "T" was $4.54 \& 4.48$, respectively, while social skills reached the lowest level in the test at 2.95 and it was not significant.

The results of group (Blog A) indicate that critical thinking is an important skill that is useful in many learning decisions. CSLab helps students to ask complex questions and using good judgment to make good decisions. And by using the blogs and discussions students should be able to make efficient decisions using critical thinking skills. This result concludes that research and investigation skills and the associated cognitive skills such as flexibility and logical reasoning, in addition to mental perseverance, have been 


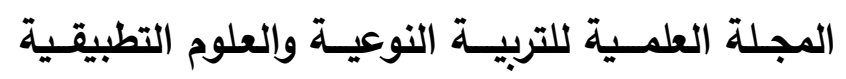

The Scientific Journal of Specific Education and Applied Sciences

developed through "Separate blogs with Detailed comments" in light of connectivism learning theory where the researchers excited students' thinking to discuss vital aspects of important issues.

It can be seen from the data in table 4 that the second experimental group that dealt with the same topics with "Sequential blogs with Detailed comments", we find that there is a close correlation between the notations and the development of critical thinking skills, where the value of " $T$ " is 5.11 for all critical thinking skills, which is a significant at the level of 0.05 which proves the effectiveness of sequential blogging in developing critical thinking skills.

In contrast to the first group, the second group Blog B, obtained significant weight of feelings, emotions, which could be evidence for understanding of our fellow man and the world is a subject that has been consciously eluded for a long time by science and scientists. And this is explained by the numerous contradictions and inaccuracies that have always clouded the problem of such feelings (Yousef, 2017).

The current study found that the interaction through sequential blogs with detailed comments led to the strengthening of personal relationships between members of the group, unlike separate blogging, and these results are consistent with what Jean Piaget said, "People are not born with social tendencies, but the association increases and social integration occurs. Gradually" (Piaget, 1976). This is what goes in the same direction with George Siemens' vision in communicative theory, as social interaction around educational topics ultimately leads to the acquisition or development of a set of habits, ideas, and trends, such as the ability to manage dialogue and the courage to express opinions as indicated by the results of the Critical Thinking Scale ( Siemens, 2006). 


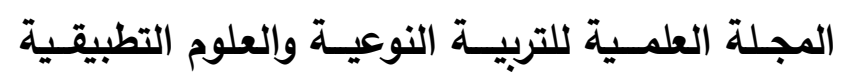

The Scientific Journal of Specific Education and Applied Sciences

However, it is true that all of us are, in some way, "experts in feelings" and, even, it is also true that we live all our lives, as Hermann Hesse said, essentially "through feelings" (Hesse, 1927). Although, on the other hand, we do not know, or at least science does not know for sure, what a feeling is, what is its meaning and how it acts. Given that feelings are routinely viewed as ungraspable, irrational, and disturbing, we admit that they should be removed as much as possible from any "objective thinking." From this we deduce that any intention to understand the other or the world appears to us distorted and exclusively cerebral, which has profound implications not only with regard to our attitude towards the world in general but also towards our therapeutic approach.

The most obvious finding to emerge from the analysis of group $\mathrm{C}$, is that the separate blogs with concise comments helped to develop all aspects of the critical thinking scale. Confirms that condensed summary comments when employed separately help develop critical thinking skills, as shown by detailed results in Table (5). This study confirms that the most important step in developing critical thinking skills is to become a critic of your own thoughts and actions, without self-reflection, there can be no growth. The finding was also reported that, students become self-critical when they recognizing their strengths, weaknesses, personal preferences, and biases, when they know this information, they can understand and why they approach certain situations from a specific perspective, and then they can change that point of view because they are aware of their presence.

On the other side, in the fourth experimental group where the interaction was through the sequential blogs associated with the concise comments, they came completely different from the previous three groups, they were not significant, except for only two sub-skills (logical reasoning and the generation of solutions) due to the fact that the brief comments depend on Brainstorming is more 


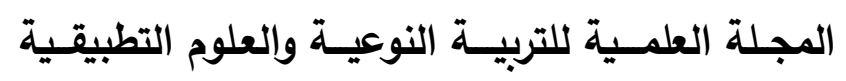

The Scientific Journal of Specific Education and Applied Sciences

than searching for information, and by reviewing the results in Table (6), we find that the sequential blogging style associated with the concise comments is not related to developing critical thinking skills, as the correlation results were lower than other groups.

By testing the assumptions of critical thinking to try to answer the question, are the thinking skills affected by the method of notations, by extrapolating the results in Table (7), it becomes clear that there are no differences between the experimental groups in the scores of the scale of critical thinking, where the value of $(F)$ calculated for the results of the scale in a comprehensive way (2.40) It is not significant at the level (0.05), which indicates that there is no difference between the four groups in the method used to develop critical thinking.

Turning now to the experimental evidence on the second hypothesis "The different of the size of the group involved in blogging discussions (large vs. medium vs. small) are significantly affecting the development of critical thinking skills" Let us now consider the size of the groups in the current study, we find that the first and second group were medium in number as well as the size of the discussion as it included (13) members in each group, while for the third group it was the smallest among the groups the number of participants was (10), While the fourth group differed as it was the largest in terms of the number of posts and the number of members, it reached (17) participants. Therefore, we find that students in small and medium groups have a higher ability to acquire critical thinking skills where the student can carefully reflect on the ideas of his colleagues, and can distinguish between the causes and factors that led to the occurrence of a specific phenomenon, taking into account his ability to make comparisons between the elements of different issues and ideas, or determining the correlative or causal relations between the evidence and the evidence, due to their ability to follow all the participations, and this is what the results showed 


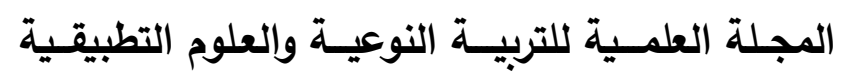

The Scientific Journal of Specific Education and Applied Sciences

in tables $(3,4,5)$, as its results are a function of the overall scale of critical thinking. While the opposite is in the large groups, where we find that the intensity of the posts in the fourth group was massive, due to the large group size (17) students, has negatively affected their ability to follow all the publications, as well as the possibility of criticizing the arguments, and providing proofs. The results of the Critical Thinking Scale for this group are not significant.

\section{Conclusion}

Higher education institutions have pursued a wide range of approaches over the past decade to increase the social communication skills of the learners. Recently there has been a renewed interest in social network such as blogs and wikis in the educational context. Online resources can be used to enhance teaching and knowledge sharing between teachers and students. The purpose of the current study was to investigate whether the social interaction patterns influence how critical thinking is constructed based on connectivism learning theory. Moreover, how does the size of the group and the different design of blog post characteristics influence student critical thinking skills? CSLab was developed as blog-based learning platform where students interact with their peers and learn from each other's. The population of this study consists of blog posts and comments posted on various CSLab blogs. The sample was 53 students who completed all the tasks throughout the 21-day period of the study. The most obvious finding to emerge from the analysis was that critical thinking skills have been developed in groups A, B, and C. However, the results of this study did not show any significant improvement in group D. The benefit of collaboration learning among students is unquestionable and its need more investigation to find the best practices. Notwithstanding the relatively limited sample, this work offers valuable insights into taking advantage of electronic blogs 


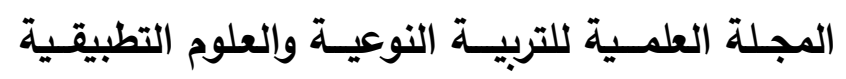

The Scientific Journal of Specific Education and Applied Sciences

and training in how to use them in the educational process, especially in developing thinking skills through small participatory groups.

\section{References}

Brooke, J. (2013). SUS: a retrospective. Journal of usability studies, 8(2), 29-40.

Brookfield, S. (2020). Teaching for critical thinking. In Handbook of Research on Ethical Challenges in Higher Education Leadership and Administration (pp. 229-245). IGI Global.

Chamberlain, E. (2017). Extending the classroom walls: using academic blogging as an intervention strategy to improve critical literacy skills with elementary students. Education 3-13, 45(2), 243-257.

Ennis, R. H. (1993). Critical thinking assessment. Theory into practice, 32(3), 179-186.

Halverson, L. R., Graham, C. R. (2019). Learner engagement in blended learning environments: A conceptual framework. Online Learning, 23(2), $145-178$.

Hesse, H., Die Nürnberger Reise, Berlín, 1927, p. 43.

Johnson, L. F., \& Levine, A. H. (2008). Virtual worlds: Inherently immersive, highly social learning spaces. Theory Into Practice, 47(2), 161-170.

Kim, H. N. (2008). The phenomenon of blogs and theoretical model of blog use in educational contexts. Computers \& Education, 51(3), 13421352.

Levitin, D. J. (2016). A field guide to lies: Critical thinking in the information age. Penguin.

Luckin, R., Clark, W., Graber, R., Logan, K., Mee, A., \& Oliver, M. (2009). Do Web 2.0 tools really open the door to learning? Practices, perceptions and profiles of 11-16-year-old students. Learning, Media and Technology, 34(2), 87-104. 


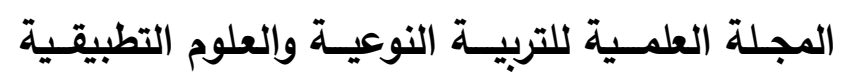

The Scientific Journal of Specific Education and Applied Sciences

Paul, R., \& Elder, L. (2019). The miniature guide to critical thinking concepts and tools. Rowman \& Littlefield.

Piaget, J. (1976). Piaget's theory. In Piaget and his school (pp. 11-23). Springer, Berlin, Heidelberg

Sefelin, R., Tscheligi, M., \& Giller, V. (2003, April). Paper prototypingwhat is it good for? A comparison of paper-and computer-based lowfidelity prototyping. In $\mathrm{CHI}^{\prime} \mathrm{O} 3$ extended abstracts on Human factors in computing systems (pp. 778-779).

Siemens, G. (2004). Connectivism: A learning theory for the digital age. Retrieved from http://www.elearnspace.org/Articles/connectivism.htm

Siemens, G. (2006). Knowing knowledge. Lulu. com.

Sun, P. C., Tsai, R. J., Finger, G., Chen, Y. Y., \& Yeh, D. (2008). What drives a successful e-Learning? An empirical investigation of the critical factors influencing learner satisfaction. Computers \& education, 50(4), 1183-1202.

Wang, Y. S., Li, C. R., Lin, H. H., \& Shih, Y. W. (2014). The measurement and dimensionality of e-learning blog satisfaction: two-stage development and validation. Internet Research, 24(5), 546-565.

Yin, R. K. (2017). Case study research and applications: Design and methods. Sage publications.

Yousef, A. M. F. (2017). Personalized Links Recommendation Based on Learning Analytics in MOOCs. In Proc. eLmL 2017: The Ninth International Conference on Mobile, Hybrid, and On-line Learning, pp. 115-119.

Yousef, A. M. F., Chatti, M. A., Schroeder, U., \& Wosnitza, M. (2014, July). What drives a successful MOOC? An empirical examination of criteria to assure design quality of MOOCs. In 2014 IEEE 14th International Conference on Advanced Learning Technologies (pp. 4448). IEEE.

Yousef, A. M. F., Rößling, G. (2013). How to Design Good Educational Blogs in LMS?. In Proc. CSEDU 2013 conference, pp. 70-75. INSTICC, 2013. 


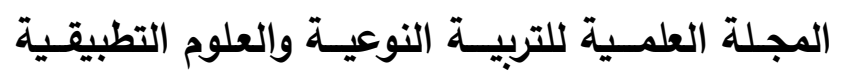

\section{The Scientific Journal of Specific Education and Applied Sciences}

Yousef, A. M. F., Salah, R. A., Makram, E. M. (2020). Investigating Different Educational Blog Characteristics to Support Collaborative Learning based on Connectivism Learning Theory. Proceedings of CSEDU 2020.

Bates, A. T. (2018). Teaching in a digital age: Guidelines for designing teaching and learning.

Garcia, E., Brown, M., \& Elbeltagi, I. (2013). Learning Within a Connectivist Educational Collective Blog Model: A Case Study of UK Higher Education. Electronic Journal of E-learning, 11(3), 253-262.

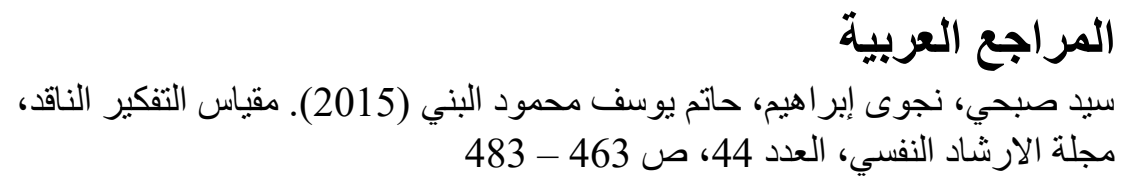




\title{
المجـلة العلمـية للتربيـة النوعيـة والعلوم التطبيقـية
}

\section{The Scientific Journal of Specific Education and Applied Sciences}

\section{كيف يؤثر حجم المجموعة وخصائص المدونة على التفكير الناقد في المناقشات عبر الإنترنت}

\author{
رضوى أمير صلاح سيد \\ قسم تكنولوجيا التعليم ـ كلية التربية النوعية ـ جامعة الفيوم \\ ملخص البحث
}

يهدف البحث الحالي إلى الكثف عن أثر التفاعل بين أساليب التدوين الالكتروني (المنفصلة والمتسلسلة) ونمط التعليقات (موجز وتفصيلي) على تنمية مهارات التفكير الناقد وكيف يؤثر حجم المجموعة وخصائص المدونة على التفكير الناقد في المناقتات عبر الإنترنت لدى طلاب تكنولوجيا التعليم. ومن أجل هذا تم تصميم بيئة تعلم تشاركي قائمة على المدونات التعليمية وفق معايير دولية، واستخدم المنهج الوصفي و المنهج شبه التجريبي، وزعت عينة البحث على أربع مجموعات تجريبية وفق أسلوب التدوين ونمط التعليقات، مجموعة (أ) تفاعلت من خلال التدوينات المنفصلة ونمط التعليق التفصيلي، و المجموعة (ب) تفاعلت من خلال التدوينات المنسلسلة ونمط التعليق التفصيلي، بينما المجموعة (ج) تفاعلت من خلال التدوينات المنفصلة ونمط التعليق الموجز، والمجموعة (د) التدوينات المنسلسلة ونمط التعليق الموجز. اسفرت النتائج عن فعالية أساليب التدوين المختلفة في المجموعات (أ، ب، ج) في تنمية مهارات التفكير الناقد، بينما جاءت النتائج غير دالة للمجموعة التجريبية الرابعة، وتضمن البحث الحالي بعض التوصيات و المقترحات للاستفادة من نتائجه في مؤسسات التعليم العالي.

الكلمات المفتاحية: التدوين الالكتروني، الانخر اط في التعلم، النظرية الاتصالية، التفكير 